\title{
Functional Activity of Macrophage Cells in the Assessment of Reaction to Biodegradable Implants
}

\author{
Natalia G. Menzyanova, \\ Elena D. Nikolaeva, Daria V. Chernobrovkina, \\ Anna M. Shershneva and Ekaterina I. Shishatskaya* \\ Siberian Federal University \\ 79 Svobodny, Krasnoyarsk, 660041, Russia
}

Received 08.02.2015, received in revised form 19.03.2015, accepted 21.05.2015

These studies suggest that manipulation of the structural and surface characteristics of synthetic scaffold materials can affect macrophage phenotype. Specifically, some of these manipulations appear to alter the macrophage response and are also associated with improved outcomes. Another manner in which biomaterials can be tailored to promote shifts in macrophage phenotype is through the use of biologically active molecules such as growth factors and cytokines.

Keywords: monocytes, macrophages, nanoparticles, cell adhesion in vitro.

\section{Показатели функциональной активности макрофагальных клеток в оценке реакции на биоразрушаемые имплантаты}

Н.Г. Мензянова, Е.Д. Николаева, Д.В. Чернобровкина, А.М. Шершнева, Е.И. Шишацкая Сибирский федеральный университет Россия, 660041, Красноярск, пр. Свободный, 79

Показано, что манипулирование структурными и поверхностными характеристиками у каркасных синтетических материалов в тканевой инженерии может влиять на фенотип

(c) Siberian Federal University. All rights reserved

* Corresponding author E-mail address: shishatskaya@inbox.ru 
макрофагов. В частности, выявлено, что некоторые параметры подложки влияют на ответ макрофагов, формируя благоприятную реакцию. С другой сторонь, показана возможность адаптировать биоматериаль для изменения фенотипа макрофагов с синтезом биологически активных молекул, таких как факторы роста и ичитокины.

Ключевые слова: моночиты, макрофаги, наночастицьь, клеточная адгезия іп vitro.

\section{Введение}

Успешное развитие технологий инжиниринга тканей в значительной степени зависит от биоматериалов, пригодных для имитирования морфологии и функции экстраклеточного матрикса. Эта структурная «мимикрия» индуцирует процессы пролиферации и дифференцировки стволовых клеток, процессы ангиогенеза, нейрогенеза, остеогенеза in vitro и in vivo (Bosil et al., 2015; Jacob et al., 2015; Quinlan et al., 2015; Gandhimathi et al., 2015). Одним из важнейших требований, предъявляемых к биоматериалам, является сочетание их высокой механической прочности для обеспечения развития ткани de novo и соответствующей скорости гистогенеза и биодеградации (Kane et al., 2015). Процессы биодеградации имплантатов связаны с системой макрофагальных клеток. Имплантированный in vivo материал распознается макрофагальной системой как чужеродная субстанция (Damanik et al., 2014; Trindade et al., 2014; Zandstra et al., 2014; Anderson, 2015; Majd et al., 2015). Структурно-функциональные особенности биоматериала и индивидуальные особенности макрофагальной системы реципиента определяют «судьбу» импланта in vivo: формирование либо состояния толерантности, либо очагов хронического воспаления. Макрофаги с фенотипом M1 участвуют в реализации провоспалительных реакций: синтезируют цитокины интерлейкин-1 $\beta$ и интерлейкин-6, фактор некроза опухолей. Макрофаги с фенотипом М2 экспрессируют скавенджер-рецепторы, продуцируют хемокины и факторы роста, которые индуцируют процессы ангиогенеза и тканевой репарации (Brown et al., 2012; Garg et al., 2013; Sussman et al., 2014; Wolf et al., 2014; Moore et al., 2015). Преобладание популяции макрофагов М1 может приводить к серьезным повреждениям тканей, препятствовать интеграции имплантата in situ.

Для прогнозирования индивидуальных реакций макрофагальной системы на биоимплантаты необходим предварительный скрининг in vitro. Показано, что в системе in vitro моноциты могут дифференцироваться в макрофаги с фенотипом M1 и M2 (Damanik et al., 2014; Grotenhuis et al., 2014). Соотношение фенотипов in vitro также зависит от типа биоматериала и варьирует у различных доноров. Это позволяет предположить, что культивирование моноцитов крови в присутствии биоматериалов является адекватной системой оценки реактивности макрофагальной системы. Также в системе in vitro можно разрабатывать технологии регуляции соотношения функциональных фенотипов M1/M2 и программировать реакции макрофагальной системы на имплантаты.

В работе изучали особенности взаимодействия моноцитов донорской крови с синтетическим биоматериалом на основе природных полигидроксиалканоатов в форме наночастиц и нанофибрилл. Системы наночастиц и нанофибрилл формируют различные 3D-структуры на микро- и на наноуровнях 
(McKeon-Fischer and Freeman, 2011; McKeonFischer et al., 2015; Vakilian et al., 2015), что может определять вариабельность процессов адгезии моноцитов, их активации, а впоследствии и вариабельность функциональных фенотипов макрофагов (Saino et al., 2011; Bota et al., 2010). Это определяет особую актуальность изучения влияния микротопографии биоматериалов на процессы дифференцировки моноцитов-макрофагов.

\section{Материалы и методы}

Выделение моноцитов

из донорской крови

Моноциты выделяли центрифугированием лекоцитарной массы в гипертоническом градиенте плотности фиколл-урографина (Recalde, 1984). Центрифугировали венозную кровь с ЭДТА, 2 мг/мл, 300 g, 15 мин. Собирали плазму и повторно центрифугировали для частичного удаления тромбоцитов. С поверхности эритроцитарной массы собирали лейкоцитарную пленку и суспендировали в плазме (после осаждения тромбоцитов). К полученной клеточной суспензии трехкратно добавляли раствор $9 \% \mathrm{NaCl}: 5$ мкл на 1 мл лейкомассы, 10 мкл на 1 мл лейкомассы, 10 мкл на 1 мл лейкомассы, с инкубацией по 10 мин при $37^{\circ} \mathrm{C}$. Лейкомассу разводили равным объемом DMEM, Gibco, с добавлением 25 мкл/мл $9 \% \mathrm{NaC1}$.

Моноциты выделяли на градиенте плот-

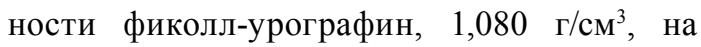
один объем фиколл-урографина наслаивали 3 объема лейкомассы и центрифугировали при 400 g 15 мин. Фракция моноцитов после центрифугирования локализовалась в интерфазном кольце. Моноциты собирали и промывали средой DMEM. В аликвоты вносили $0,1 \%$ метиленовый синий $1: 1$ по объему и подсчитывали неокрашенные клетки в камере Горяева.
Определение активности

альфа-нафтилаиетатэстеразы

Моноциты суспендировали в среде DMEM, аликвоты клеточных суспензий наносили на предметные стекла и инкубировали во влажной камере 1 ч при $37^{\circ} \mathrm{C}$. Далее удаляли среду и фиксировали препараты в парах формалина. Гистохимическую реакцию на альфа-нафтилацетатэстеразу проводили по методу Burstone (1957).

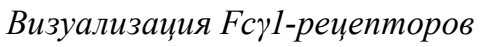
и с3bi-peųепторов

Fc $\gamma 1$-рецепторы и с3bi-рецепторы визуализировали с помощью наночастиц золота. Раствор наночастиц готовили по методу Хомутовского и др. (1986). Наночастицы размером 15-20 нм стабилизировали протеином А из стенки Staphylococcus aureus по методу, описанному Baschong et al. (1985). Моноциты фиксировали 0,1\%-ным глютаровым альдегидом. Клетки промывали дважды $0,1 \mathrm{M}$ фосфатным буфером с $\mathrm{pH}=7,2$ и обрабатывали клеточные суспензии по схемам А и Б.

А. Визуализация c3bi-рецепторов последовательно включала: инкубацию клеток с IgG человека (GIBCO, США); инкубацию клеток с моноклональными антителами ИКО ГМ (к $\alpha$-цепи с3bi-рецептора, Abcam, UK); инкубацию с конъюгатом протеин А-наночастицы золота.

Б. Визуализация Fc $\gamma 1$-рецепторов последовательно включала: инкубацию клеток с $\operatorname{IgG}$ человека; инкубацию с кроличьей антисывороткой к IgG человека (Sigma, CША); инкубацию с конъюгатом протеин А-наночастицы золота.

На всех этапах продолжительность инкубации составляла 1 ч при комнатной температуре. После каждой инкубации клетки промывали фосфатным буфером. 
Клетки после обработки конъюгатом протеин A-наночастицы фиксировали $0,1 \% \mathrm{OsO}_{4}$, заливали в эпон-аралдит и готовили ультратонкие срезы по общепринятым методам.

\section{Получение микроносителей}

Для конструирования микрочастиц использовали поли-3-гидроксибутират (ПЗГБ) и сополимер поли(3-гидроксибутират-со-4гидроксибутират) (ПЗГБ/4ГБ) с включением 4ГБ 10 мол. \%, синтезированные в культуре Ralstonia eutropha B5786, лаборатория хемоавтотрофного биосинтеза Института биофиЗики СО РАН.

\section{Получение микрочастии}

Микрочастицы получали методом испарения растворителя из эмульсии. Раствор полимера в $1 \%$-ном дихлорметане с добавлением сурфактанта $1 \%$-ного поливинилового спирта диспергировали в механической мешалке, оборудованной трехлопастным пропеллером и/или с помощью УЗ-генератора «Sonicator» 3000 (MisonixIncorporated, США). Для оптимизации процедуры микронизации полимерных растворов использовали распылительную сушилку B-290 Advanced (Büche, Швейцария). После испарения растворителя микросферы собирали центрифугированием при 10000 об/мин, промывали, высушивали под вакуумом и лиофилизировали MartinChristALPHA 2-4 LDplus (Martin Christ Gefriertrocknungsanlagen GmbH, Германия). Размеры полученных микрочастиц варьировали от 20 до 500 нм. Для выделения фракции до 200 нм микрочастицы суспендировали в DMEM с добавлением $10 \%$-ной фетальной телячьей сыворотки и антибиотиков (стрептомицин 100 мкг/мл, пенициллин 100 ЕД/мл (Gibco, Invitrogen, США) и фильтровали через мембранные фильтры с размером пор 200 нм (Sartorius, Германия).

\section{Адгезия моноцитов}

Моноциты ресуспендировали в среде DMEM с добавлением 10\%-ной фетальной телячьей сыворотки и раствора антибиотиков, переносили в 24-луночные культуральные планшеты, концентрация клеток 105/мл (все компоненты Gibco, Invitrogen). В контроле моноциты инкубировали на культуральном пластике. В экспериментальных вариантах в лунки культурального планшета помещали: а) полимерную пленку (1 х 1 см); б) микрочастицы ПЗГБ со средним размером 500 нм (1 мг/мл); в) микрочастицы ПЗГБ размером меньше 200 нм (1 мг/мл); г) микрочастицы П4ГБ со средним размером 500 нм (1 мг/мл). Культивирование проводили в среде DMEM в течение 24 ч в атмосфере $5 \% \mathrm{CO}_{2}$ при температуре $37^{\circ} \mathrm{C}$.

Потенциальнуюцитотоксичность микроносителей оценивали в реакции с MTT [3-(4,5-диметилтиазол-2-ил)-2,5дифенилтетразол бромидом] (Sigma). Среду заменяли на содержащую стерильный раствор МТТ-бромида, через 4 ч среду с раствором МТТ заменяли на ДМСО для растворения кристаллов МТТ-формазана. После полного растворения кристаллов супернатант переносили в 96-луночный планшет для измерения оптической плотности при 540 нм на микропланшетном фотометре Bio-Rad 680 (Bio-Rad LABORATORIES Inc., CШA). Количество клеток высчитывали по калибровочному графику.

Флуоресцентное окрашивание клеток на матриксах проводили красителями DAPI и FITC. После удаления питательной среды клетки промывали фосфатно-буферным раствором, фиксировали 10\%-ным раствором формалина, обрабатывали раствором Triton-X в фосфатно-буферном растворе. Затем клетки окрашивали FITC, 50 мкг/мл в деионизированной воде, по 1 мл раствора на 
образец, 1 час при комнатной температуре. После этого клетки окрашивали DAPI в концентрации 1 мкг/мл, по 50 мкл раствора на образец, 15 минут. После тщательного промывания фосфатно-буферным раствором образцы микроскопировали на Leica DM 6000B (Leica Microsystems, Германия).

\section{Результаты и обсуждение}

\section{Характеристика}

клеточной популячии моноцитов,

выделенных на градиенте

фиколл-урографин

Сразу после выделения при окрашивании метиленовым синим жизнеспособность клеточной популяции моноцитов достигала

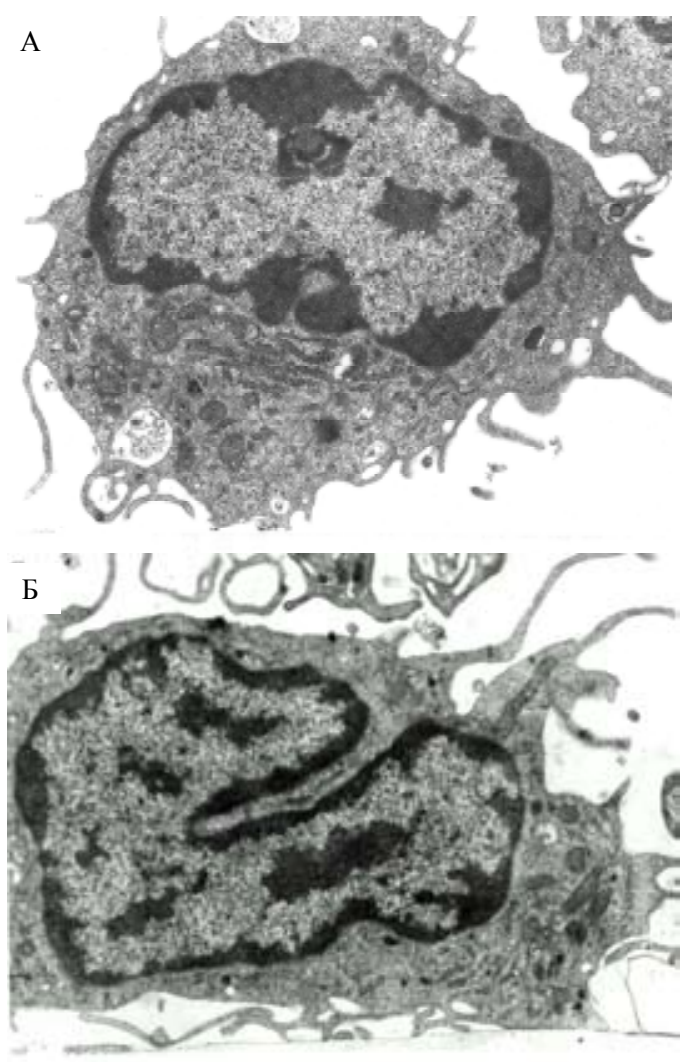

Рис. 1. Морфология моноцитов после выделения на градиенте фиколл-урографин. х16 000
95 \%. Электронная микроскопия подтвердила нативность клеток и внутриклеточных органоидов (рис. 1). Гистохимическими методами в выделенных моноцитах была выявлена высокая активность альфа-нафтилацетатэстеразы и слабая положительная реакция на пероксидазу. Цитологический анализ клеточных препаратов, окрашенных на эстеразу и пероксидазу, показал, что в выделенной на градиенте фиколл-урографин клеточной популяции численность моноцитов достигала 85-90\%. Выделенные моноциты экспрессировалиFс $\gamma 1-$ и с3bi-рецепторы (рис. 2).

\section{Адгезия моноцитов:}

адгезия на культуральном пластике

В течение первых двух с половиной часов инкубации к поверхности культурального пластика адгезировалось 36 \% клеток. Через 24 ч их количество уменьшалось до $2,7 \%$ от общего количества клеток в ячейке планшета за счет вторичного отделения клеток от подложки. Жизнеспособность адгезированных клеток через 24 часа культивирования не снижалась.

\section{Адгезия моноцитов: адгезия к ПГА-пленкам}

Через 24 часа культивирования количество адгезированных клеток на ПГА пленках было значительно выше, чем в контроле (рис. 3a, б).

\section{Адгезия моночитов: адгезия} к микрочастииам

Для оценки количества адгезированных на микрочастицах активных клеток использовали МТТ-тест (рис. 4). Количество адгезированных клеток зависело от размеров наночастиц, приготовленных из ПЗГБ. На частицах размером меньше 200 нм адгезированных клеток было в два раза больше, чем на части- 


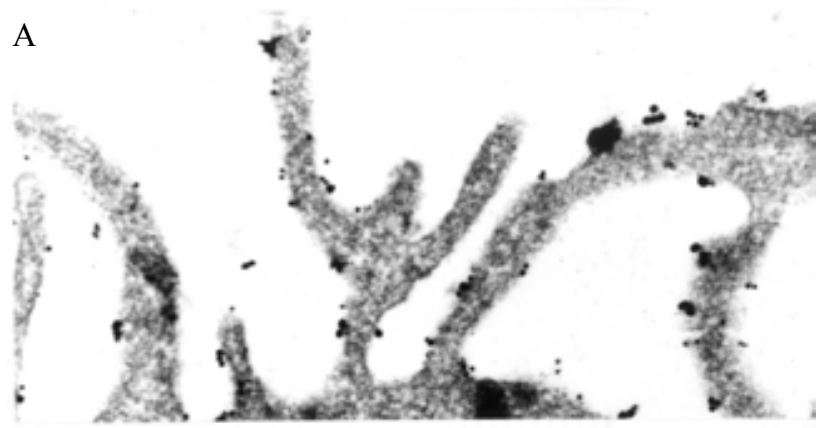

Б

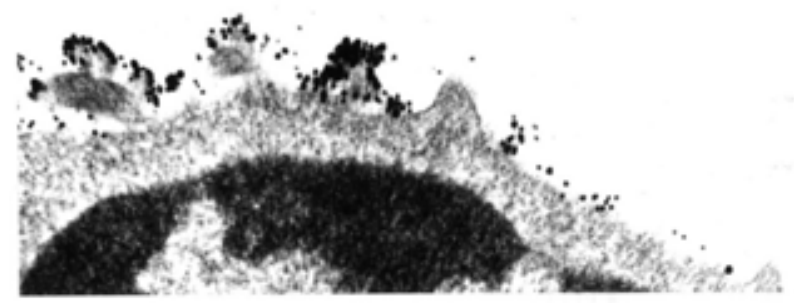

B

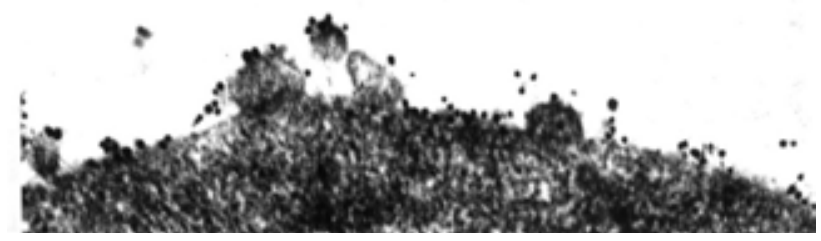

Рис. 2. Экспрессия Fc $\gamma 1-$ рецепторов (a, б) и с3bi-рецепторов (в) на мембране моноцитов после выделения на градиенте плотности фиколл-урографин. х80 000
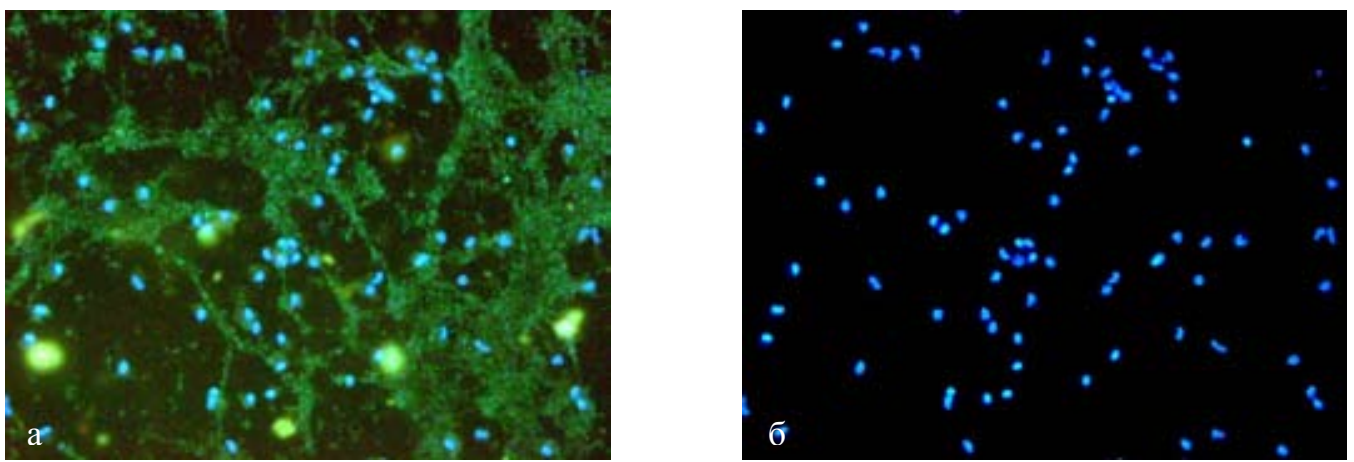

Рис. 3. Адгезия моноцитов на ПГА-пленках, инкубация 24 ч, окрашивание FITC (а) и DAPI (б) 


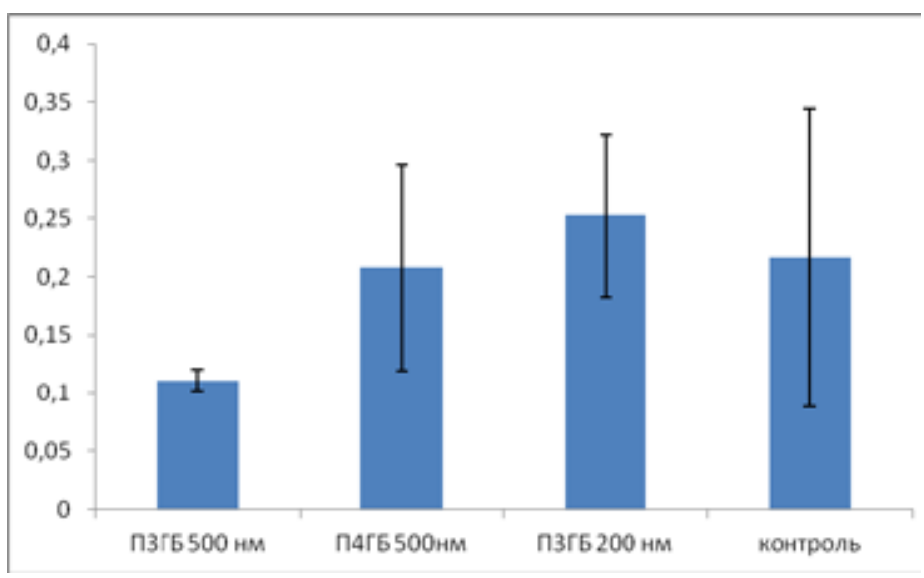

Рис. 4. Результаты МТТ-теста на наночастицах разного типа

Таблица 1. Общие характеристики полимеров

\begin{tabular}{|l|c|c|}
\hline \multicolumn{1}{|c|}{ Параметры } & \multicolumn{2}{c|}{ Полимерный материал } \\
\cline { 2 - 3 } & ПЗГБ & ПЗГБ/4ГБ \\
\hline Молекулярная средневесовая масса (Da) & 1200500 & 4100000 \\
\hline Молекулярная среднечисловая масса (Da) & 722890 & 2,32 \\
\hline Полидисперсность & 1,66 & 43 \\
\hline Кристалличность $(\%)$ & 76 & 171,9 \\
\hline Температура плавления $\left({ }^{\circ} \mathrm{C}\right)$ & 179,7 & 268 \\
\hline Температура деградации $\left({ }^{\circ} \mathrm{C}\right)$ & 273 & \\
\hline
\end{tabular}

цах размером 500 нм. Следует отметить, что количество адгезированных клеток зависело не только от размеров частиц, но и от материала (рис. 4). Так, на частицах размером 500 нм, полученных из ПЗГБ, количество адгезированных клеток было в два раза меньше, чем на частицах того же размера, полученных из П4ГБ.

Полученные результаты позволяют заключить, что in vitro адгезия неактивированных моноцитов на подложках из наночастиц зависит от их размеров, а также от типа материала.

Микрочастицы, как и нановолокна, формируют сложный рельеф контактной к клеткам поверхности. Эффективность адгезии клеток к таким наноповерхностям зависит не только от формирования различных типов нековалентных взаимодействий между химическими группировками биоматериала и структурными компонентами клеточной мембраны, но и от локальных изменений кривизны поверхности плазматической мембраны. В свою очередь, локальные изменения кривизны мембраны (положительные и отрицательные) приводят к формированию сложного нанорельефа плазматической мембраны на подложке. Показано, что физический параметр кривизны определяет функциональную активность биологических мембран, изменяя активность мембраносвязанных ферментов, систем рецепторного сигналинга (Shen et al., 2014; Ambroso et al., 2014; Larsen et al., 2015). В итоге, локальные изменения кривизны кле- 
точных мембран могут контролировать такие интегральные процессы, как дифференцировка, пролиферация, адгезия, фагоцитоз.

В связи с этим можно предположить, что различная адгезивность исследованных наночастиц обусловлена специфичностью индуцированных нанорельефом подложки локальных изменений кривизны плазматической мембраны клеток. Следствием этих локальных изменений кривизны мембраны может быть формирование специфических функциональных фенотипов адгезированных клеток на различных наноматериалах in vitro. Это позволяет использовать оценку адгезивности наноматералов для моноцитов для прогнозирования взаимодействия макрофагальной системы с биополимерными имплантами in vivo.

Работа выполнена за счет средств государственного задания на проведение фундаментальных исследований РАН (проект № гос. регистрации 01201351505).

\section{Список литературы}

1. Хомутовский О.А., Луцик М.Д., Передерей О.Ф. (1986) Электронная гистохимия рецепторов клеточных мембран. Киев: Наукова думка, 280 с. [Chomutovsky O.A., Lucik M.D., Peredrey O.Ph. (1986) Electron histochemistry of cell membrane receptors. Kiev: Naukova dumka, 280 p. (In Russian)].

2. Anderson J.M. (2015) Exploiting the inflammatory response on biomaterials research and development. Journal of materials science. Materials in medicine 26 (3):121.

3. Baschong W., Lucoeq J.M., Roth J. (1985) Thiocyonat gold: small (2-3 nm) colloidal gold affinity cytochemical labelling in electron microscopy. The journal of histochemistry and cytochemistry 85 (5): 409-411.

4. Bosi S., Rauti R., Laishram J., Turco A., Lonardoni D., Nieus T., Prato M., Scaini D., Ballerini L. (2015) From 2D to 3D: novel nanostructured scaffolds to investigate signalling in reconstructed neuronal networks. Scientific Reports 5: 9562.

5. Bota P.C., Collie A.M., Puolakkainen P., Vernon R.B., Sage E.H., Ratner B.D. (2010) Biomaterial topography alters healing in vivo and monocyte/macrophage activation in vitro. Journal of Biomedical Materials Research Part A 95(2): 649-657.

6. Brown B.N., Londono R., Tottey S., Zhang L., Kukla K.A., Wolf M.T. (2012) Macrophage phenotype as a predictor of constructive remodeling following the implantation of biologically derived surgical mesh materials. Acta Biomaterialia 8(3): 978-987.

7. Burstone M.S. (1957) The cytochemical localization of esterase. Journal of the National Cancer Institute 18(2):167-172.

8. Damanik F.F., Rothuizen T.C., van Blitterswijk C., Rotmans J.I., Moroni L. (2014) Towards an in vitro model mimicking the foreign body response: tailoring the surface properties of biomaterials to modulate extracellular matrix. Scientific Reports 4: 6325.

9. Gandhimathi C., Venugopal J.R., Tham A.Y., Ramakrishna S., Kumar S.D. (2015) Biomimetic hybrid nanofibrous substrates for mesenchymal stem cells differentiation into osteogenic cells. Materials Science \& Engineering. C, Materials for Biological Applications 49: 776-785.

10. Graham R.C., Karnovsky M.J. (1966) The early stages of absorbtion of injected horseradish peroxidase in the proximal tubules of mouse kidney: ultrastructural cytochemistry by a new technique. The Journal of Histochemistry and Cytochemistry14 (2):291-299. 
11. Grotenhuis N., vd Toom H.F.E., Kops N., Bayon Y., Deerenberg E.B., Mulder I.M., van Osch G.J.V.M., Lange J.F., Bastiaansen-Jenniskens Y.M. (2014) In vitro model to study the biomaterialdependent reaction of macrophages in an inflammatory environment. British Journal of Surgery 101: 983-992.

12. Jacob R.S., Ghosh D., Singh P.K., Basu S.K., Jha N.N., Das S., Sukul P.K., Patil S., Sathaye S., Kumar A., Chowdhury A., Malik S., Sen S., Maji S.K. (2015) Self healing hydrogels composed of amyloid nano fibrils for cell culture and stem cell differentiation. Biomaterials 54: 97-105.

13. Kane R.J., Weiss-Bilka H.E., Meagher M.J., Liu Y., Gargac J.A., Niebur G.L., Wagner D.R., Roeder R.K. (2015) Hydroxyapatite reinforced collagen scaffolds with improved architecture and mechanical properties. Acta Biomaterialia 17:16-25.

14. Majd H., Scherer S.S., Boo S., Ramondetti S., Cambridge E., Raffoul W., Friedrich M., Pittet B., Pioletti D., Hinz B., Pietramaggiori G. (2015) Novel micropatterns mechanically control fibrotic reactions at the surface of silicone implants. Biomaterials 54:136-147.

15. McKeon-Fischer K.D., Freeman J.W. (2011) Characterization of electrospun poly(L-lactide) and gold nanoparticle composite scaffolds for skeletal muscle tissue engineering. Journal of Tissue Engineering and Regenerative Medicine 5(7): 560-568.

16. McKeon-Fischer K.D., Browe D.P., Olabisi R.M., Freeman J.W. (2015) Poly(3,4ethylenedioxythiophene) nanoparticle and poly( $\varepsilon$-caprolactone) electrospun scaffold characterization for skeletal muscle regeneration. Journal of Biomedical Materials Research Part A doi: 10.1002/jbm.a.35481.

17. Moore L.B., Sawyer A.J., Charokopos A., Skokos E.A., Kyriakides T.R. (2015) Loss of monocyte chemoattractant protein-1 alters macrophage polarization and reduces NFKB activation in the foreign body response. Acta Biomaterialia 11: 37-47.

18. Recalde H.R. (1984) A simple method of obtaining monocytes in suspension. Journal of Immunological Methods 69(1): 71-77.

19. Quinlan E., Partap S., Azevedo M.M., Jell G., Stevens M.M., O’Brien F.J. (2015) Hypoxiamimicking bioactive glass/collagen glycosaminoglycan composite scaffolds to enhance angiogenesis and bone repair. Biomaterials 52: 358-366.

20. Saino E., Focarete M.L., Gualandi C., Emanuele E., Cornaglia A.I., Imbriani M. (2011) Effect of electrospun fiber diameter and alignment on macrophage activation and secretion of proinflammatory cytokines and chemokines. Biomacromolecules 12(5): 1900-1911.

21. Sussman E.M., Halpin M.C., Muster J., Moon R.T., Ratner B.D. (2014) Porous implants modulate healing and induce shifts in local macrophage polarization in the foreign body reaction. Annals of Biomedical Engineering 42(7):1508-1516.

22. Trindade R., Albrektsson T., Tengvall P., Wennerberg A. (2014) Foreign body reaction to biomaterials:on mechanisms for buildup and breakdown of osseointegration. Clinical Implant Dentistry and Related Research doi: 10.1111/cid.12274.

23. Vakilian S., Mashayekhan S., Shabani I., Khorashadizadeh M., Fallah A., Soleimani M. (2015) Structural stability and sustained release of protein from a multilayer nanofiber/ nanoparticlecomposite. International Journal of Biological Macromolecules 75: 248-257

24. Wolf M.T., Dearth C.L., Ranallo C.A., LoPresti S.T., Carey L.E., Daly K.A. (2014) Macrophage polarization in response to ECM coated polypropylene mesh. Biomaterials 35(25): 6838-6849 
25. Zandstra J., Hiemstra C., Petersen A.H., Zuidema J., van Beuge M.M., Rodriguez S., Lathuile A.A., Veldhuis G.J., Steendam R., Bank R.A., Popa E.R. (2014) Microsphere size influences the foreign body reaction. European Cells \& Materials 28: 335-347 